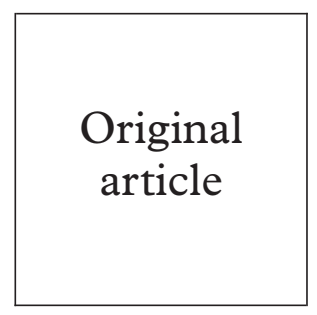

\title{
Survival by AIDS defining condition in rural Uganda
}

\author{
D Morgan, S S Malamba, J Orem, B Mayanja, M Okongo, J A G Whitworth
}

Objectives: To report the initial AIDS defining conditions, CD4 lymphocyte counts around the time of AIDS diagnosis, and survival by AIDS defining condition in a population based cohort in rural Uganda.

Methods: Participants in an HIV natural history cohort in rural Uganda were reviewed every 3 months at routine visits and at other times when they were ill. The date and nature of the first AIDS defining condition in participants developing AIDS during follow up between the start of the cohort in 1990 and the end of 1998 were noted. The CD4 count at, or within, 3 months of this time was recorded for those participants who developed AIDS (WHO stage 4) after 1993.

Results: The median survival from developing AIDS to death was 9.3 months and the median CD4 lymphocyte count around the time of developing AIDS was 150 cells $\times 10^{6} / 1$. The most frequent AIDS defining conditions were wasting syndrome, oesophageal candidiasis, and mucocutaneous herpes simplex virus infection (HSV) for more than 1 month. The median survival with wasting syndrome, Kaposi's sarcoma, and oesophageal candidiasis was less than 3.5 months; however, survival with cryptosporidial diarrhoea, chronic HSV, and extrapulmonary tuberculosis was greater than 20 months. There was little relation between CD4 count around the time of development of the AIDS defining condition and the median survival with that condition.

Conclusions: The survival for most AIDS defining conditions was generally shorter and the median CD4 lymphocyte count higher than studies reported from developed countries. However, the conditions with the longest survival (cryptosporidial diarrhoea, chronic HSV, and extrapulmonary tuberculosis) had a similar survival to that in developed countries and these conditions have a high background level in this population.

(Sex Transm Inf 2000;76:193-197)

Keywords: AIDS; survival; Africa

\section{Introduction}

Survival with AIDS has been shown to vary greatly, but generally the median survival in developed countries before the use of highly active antiretroviral therapy (HAART) was estimated to be between 12 and 18 months. ${ }^{1}$ Studies have found that the nature of the AIDS defining condition (ADC) was as important as age at seroconversion and CD4 lymphocyte level in predicting survival ${ }^{1-4}$ and estimates of median survival after a single ADC ranged from 3-31 months depending on the disease. ${ }^{5}$

The widespread use of effective chemoprophylaxis for opportunistic infections and, more recently, the use of antiretroviral therapy have resulted in a delay in the onset of AIDS, ${ }^{6}$ a longer survival with AIDS, ${ }^{7}$ and a change in the frequency of specific ADC, ${ }^{89}$ many of which are now occurring at lower CD4 lymphocyte counts. ${ }^{10}$

There have been few reports of survival with AIDS from less developed countries, but those that have been published suggest a much shorter survival time. ${ }^{11} 12$

In this paper we report survival times and CD4 lymphocyte counts by initial ADC in a rural population based cohort in Uganda, where the main mode of HIV transmission is heterosexual intercourse and chemoprophylaxis for opportunistic infections and antiretroviral drugs are not available.

\section{Methods}

The natural history cohort recruits participants from a large population cohort in rural Uganda and has been described in detail elsewhere. ${ }^{13}$ HIV infected participants are prevalent cases of infection who were identified as being HIV positive in 1989-90 and incident cases with estimated dates of seroconversion between 1990 and 1997. Age stratified HIV negative controls for the prevalent and incident cases were also enrolled. Participants are seen routinely at 3 monthly intervals by one of two clinicians who are blind to their HIV status. At each visit they are staged using the proposed WHO staging system ${ }^{14}$ by a computer algorithm. AIDS was taken as WHO stage 4 and the two terms are used synonymously in this paper. Participants also attend the clinic for investigation and treatment if they are ill at other times. If they attended with an initial ADC between routine visits, this date was taken as their date of entry into stage 4 . This study includes participants developing AIDS up to the end of 1998.

\section{DIAGNOSTIC METHODS}

Wasting syndrome was defined as more than $10 \%$ documented loss of body weight and either unexplained chronic diarrhoea $(>1$ month), or chronic weakness and unexplained prolonged fever ( $>1$ month) with pyrexia recorded on at least one occasion. Crypto- 
sporidiosis was diagnosed by modified ZiehlNeelsen stain on faecal smear; cryptococcal infection was diagnosed on Indian ink stain of CSF; herpes simplex and oesophageal candidiasis were diagnosed clinically; extrapulmonary tuberculosis was diagnosed by the presence of acid fast bacilli from a lymph node, or a pleural effusion with a lymphocytosis which responded to antituberculous treatment; Kaposi's sarcoma was mostly confirmed histologically although some cases were diagnosed clinically. Microbiology services became available in mid-1996. Basic radiology services were available intermittently at a local hospital 15 $\mathrm{km}$ away.

\section{CD4 LYMPHOCYTE ESTIMATIONS}

T cell subset analyses are estimated every 6 months in HIV positive participants by Facscount (Becton Dickinson). The CD4 lymphocyte results included in this paper are the CD 4 counts at the time or within 3 months of having entered stage 4. CD4 lymphocyte counts are not available for all participants because these only became available after the first 3 years of the study; some may have failed or the participant may have delayed attending their next routine appointment when they were due for a CD4 estimation.

STATISTICAL METHODS

Only those who developed AIDS during follow up are included in the analyses and participants already in stage 4 when first seen were excluded. Kaplan-Meier analysis was used to determine survival from the date first seen with an ADC to death. If a person developed AIDS for more than one reason, they contributed to each reason.

All analyses were performed using the STATA statistical package (Stata Corporation, TX, USA).

\section{Results}

By the end of 1998, 107 prevalent and 141 incident cases of HIV infection, and 236 HIV negative controls had been enrolled into the cohort. Seventy two participants (43 prevalent and 29 incident cases) had developed AIDS during follow up, of whom 52 had died. The age and sex of these participants when seen with AIDS are shown in table 1. Overall, the mean age of the 38 males (36.9 years) was similar to that in the 34 females (36.5 years). The incident cases who developed AIDS had a median (95\% confidence interval (CI)) of 48.8 $(31.8,52.4)$ months between seroconversion and first being seen with AIDS.

Table 1 Age and sex of participants seen with AIDS

\begin{tabular}{lllllll}
\hline \multirow{2}{*}{$\begin{array}{l}\text { Age group } \\
\text { (years) }\end{array}$} & \multicolumn{2}{l}{ Prevalent cases } & & \multicolumn{2}{l}{ Incident cases } & \\
\cline { 2 - 3 } & Male & Female & & Male & Female & Total \\
\hline $15-24$ & 1 & 4 & & 1 & 3 & 9 \\
$25-34$ & 11 & 7 & & 4 & 27 \\
$35-44$ & 11 & 2 & & 3 & 3 & 19 \\
$45-54$ & 2 & 3 & & 3 & 5 & 13 \\
55 and over & 0 & 2 & & 1 & 1 & 4 \\
Total & 25 & 18 & & 13 & 16 & 72 \\
Mean age & 35.5 & 35.2 & & 39.6 & 38.0 & 36.7 \\
(range) & $(24-50)$ & $(20-57)$ & & $(23-71)$ & $(19-65)$ & $(19-71)$ \\
\hline
\end{tabular}

Table 2 Reasons for developing AIDS and survival by initial AIDS defining condition

\begin{tabular}{|c|c|c|}
\hline AIDS defining category & Number & $\begin{array}{l}\text { Median survival } \\
\text { (months) } \\
\text { (95\% CI) }\end{array}$ \\
\hline All conditions & 72 & $9.3(4.3,17.3)$ \\
\hline HIV wasting syndrome & 27 & $3.4(1.9,9.7)$ \\
\hline \multicolumn{3}{|l|}{ Cryptosporidial diarrhoea } \\
\hline$>1$ month & 5 & $21.1(2.0,-)$ \\
\hline Cryptococcal meningitis & 1 & $2.0^{\star}$ \\
\hline \multicolumn{3}{|l|}{ Mucocutaneous HSV infection } \\
\hline$>1$ month & 13 & $20.1(6.7,-)$ \\
\hline Candidiasis of the oesophagus & 19 & $3.1(1.1,8.9)$ \\
\hline Extrapulmonary TB & 7 & $>24(4.1,-)$ \\
\hline Salmonella septicaemia & 1 & $7.0^{\star}$ \\
\hline Kaposi's sarcoma & 8 & $3.1(1.3,11.4)$ \\
\hline
\end{tabular}

^Actual value.

The first ADCs seen in the 72 participants who progressed to AIDS are shown in table 2. Seven participants had two conditions, and one participant had three conditions for developing AIDS. The prevalent and incident cases had similar ADCs and so these groups were combined. Wasting syndrome was the commonest reason for developing AIDS followed by oesophageal candidiasis. The overall median survival from developing AIDS was 9.3 months. The incident cases had a longer median survival $(95 \% \mathrm{CI})$ compared with the prevalent cases $(20.7(3.7,>30)$ months and $9.3(3.7,12.9)$ months respectively) but this was not significant $\left(\chi^{2} 1.55, p=0.2, \log\right.$ rank test). The median survival of the participants from developing each initial ADC is also shown in table 2. Wasting syndrome, oesophageal candidiasis, and Kaposi's sarcoma all had a short survival time of about 3 months, whereas mucocutaneous HSV infection or cryptosporidial diarrhoea for more than 1 month had median survival times of over 20 months. The median survival time after the diagnosis of extrapulmonary tuberculosis was not reached, but is likely to be over 24 months. Only one person developed AIDS because of extrapulmonary cryptococcal infection and one because of salmonella septicaemia, and their actual survival times are shown.

Overall, the median CD4 lymphocyte count around the time of developing AIDS was 150 cells $\times 10^{6} / 1$, but this varied from 101 cells $\times 10^{6} / 1$ for participants with candidiasis of the oesophagus to 270 cells $\times 10^{6} / 1$ for those presenting with extrapulmonary tuberculosis (table 3 ). There was little relation between survival and CD 4 count for each condition as shown in figure 1 .

Table 3 CD4 lymphocyte count at the time or within 3 months of developing AIDS

\begin{tabular}{lll}
\hline AIDS defining category & $\begin{array}{l}\text { No with } \\
\text { CD4 count }\end{array}$ & $\begin{array}{l}\text { Median CD4 } \\
(95 \% \text { CI) }\end{array}$ \\
\hline All conditions & 49 & $150(77,239)$ \\
HIV wasting syndrome & 13 & $150(75,427)$ \\
Cryptosporidial diarrhoea & & $154(4,727)$ \\
$\quad>1$ month & 4 & $3^{\star}$ \\
Cryptococcal meningitis & 1 & $140(40,592)$ \\
Mucocutaneous HSV infection & 11 & $101(29,280)$ \\
$\quad>1$ month & 10 & $270(23,569)$ \\
Candidiasis of the oesophagus & 6 & $222^{\star}$ \\
Extrapulmonary TB & 1 & $208(20,514)$ \\
Salmonella septicaemia & 5 & \\
Kaposi's sarcoma & & \\
\hline
\end{tabular}

^Actual value. 


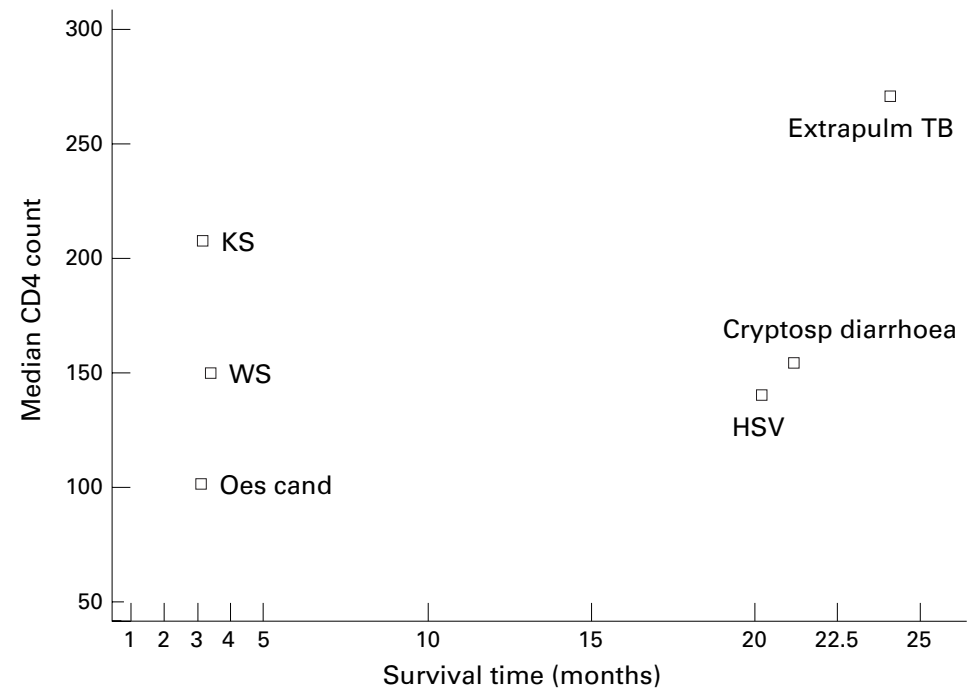

Figure 1 Survival by AIDS defining and CD4 lymphocyte count around the time of developing that condition. $K S=K a p o s i$ 's sarcoma; $W S=$ wasting syndrome; Oes cand $=$ oesophageal candidiasis; HSV = mucocutaneous herpes simplex infection for more than 1 month; Crytosp diarrhoea = cryptosporidial diarrhoea for more than 1 month; Extrapulm $T B=$ extrapulmonary tuberculosis.

The median survival (95\% CI) of $73 \mathrm{HIV}$ infected participants who had at least one CD4 count of less than 200 cells $\times 10^{6} / 1$ was 17.1 $(11.1,22.0)$ months.

Eleven HIV negative controls developed conditions which are classified as AIDs defining-four had cryptosporidial diarrhoea and seven had HSV for more than 1 month. None died during follow up.

\section{Discussion}

The median survival from developing AIDS in this rural African cohort was only 9.3 months. This may be an underestimate of the true survival because the incident cases who developed AIDS did so a median of 49 months after seroconversion. Since this is faster than the median time to AIDS for the incident cases as a whole (currently more than 8 years) they may represent rapid progressors. Although short, the survival in this cohort is similar to that of around 10 months in developed countries early in the HIV epidemic. ${ }^{415}{ }^{16}$ However, the course of AIDS in developed countries changed with better management of HIV infection owing to the use of prophylaxis and antiretrovirals. Survival after an AIDS diagnosis in the United Kingdom increased from 10.6 months before 1987 to over 19 months in $1991^{17}$ and in Italian haemophiliacs it increased from 12 months in 1983-8 to 25 months in $1990-1 .^{18}$ With HAART both the incidence of AIDS has been reduced further and the survival with AIDS has been prolonged. ${ }^{19} 20$

RANKING OF ADCS

Pneumocystis carinii pneumonia (PCP) has been by far the commonest AIDS defining diagnosis in developed countries with around half of AIDS cases in most reported studies presenting with this condition regardless of sex or mode of transmission..$^{51-24}$ We did not diagnose PCP in any of our participants, but our findings are consistent with another study in Uganda. ${ }^{25}$ Although PCP has been identified as a cause of pneumonia in AIDS patients in Africa ${ }^{26}$ the frequency is much lower than that reported from North America and Europe. In the United Kingdom only $14 \%$ of black African women had PCP as their first ADC compared with $38 \%$ of white women, while more African women had pulmonary and extrapulmonary TB $(23 \%$ and $14 \%$ respectively compared with $5 \%$ and $0 \%$ in white women). ${ }^{27}$ This could reflect different racial susceptibility or since the paper did not state how long the African women had resided in Britain, the prevalence of the conditions in their home countries. Patterns of ADCs have changed over the years in developed countries since chemoprophylaxis for opportunistic infections were introduced as standard care for HIV infected people with a low CD4, and more recently with the use of antiretroviral drugs. ${ }^{10}$ The frequency of PCP as the primary ADC fell from representing $64 \%$ of ADCs in $1982-6$ to $20 \%$ in $1992-6$, and as the frequency of PCP fell, so wasting syndrome and oesophageal candidiasis increased over this time from $2 \%$ and $7 \%$ of $\mathrm{ADCs}$ to $16 \%$ and $13 \%$ respectively. ${ }^{5}$

Besides the time element, the commonest reported ADCs and survival depend on the source of recruitment (for example, cohort with regular follow up or hospital inpatients) and the structure of population studied. In a homosexual cohort described by Saah, Kaposi's sarcoma represented $22 \%$ of $\mathrm{ADC}^{24}$ whereas it occurred in only $2 \%$ of a heterosexual cohort. ${ }^{22}$ As well as being commoner in homosexuals, Kaposi's sarcoma is endemic in many African countries such as Uganda. In a large cohort in London, over half of whom were Africans, $15 \%$ presented with Kaposi's sarcoma which is similar to the proportion in our study. ${ }^{3}$ Our commonest ADC was wasting syndrome, and although other studies have reported up to $20 \%{ }^{23}$ of adults having this condition as their initial ADC, in our cohort this may represent conditions such as malignant conditions and tuberculosis which we could not always diagnose in a rural situation with basic laboratory facilities. The doctors reviewing the participants were blind to their HIV status or CD 4 count, and therefore the bias of diagnosing HIV/AIDS related conditions because they knew the participant was HIV infected was reduced.

SURVIVAL AND CD4 COUNT BY ADC

The median CD4 lymphocyte count of our participants at or around the time of developing AIDS was 150 cells $\times 10^{6} / 1$, and this is higher than studies from developed countries. The median CD4 count at initial AIDS defining diagnosis in developed countries has declined over time from around 100 cells $\times 10^{6} / 1$ early in the epidemic ${ }^{128}$ to $40-64$ cells $\times 10^{6} / 1$ more recently. ${ }^{1029-31}$ A recent study from Thailand found that heterosexuals who developed AIDS had a median CD 4 count of 53 cells $\times 10^{6} / 1$. $^{32}$

The CD4 counts at which individuals develop specific AIDS defining conditions vary. In our study, the median CD4 counts for individuals presenting with wasting syndrome, 
oesophageal candidiasis, and Kaposi's sarcoma were higher than other studies ${ }^{10} 3033$ but chronic HSV infections developed at similar CD4 counts. Tuberculosis is difficult to compare-we used extrapulmonary $\mathrm{TB}$ as defined for stage 4 by the WHO clinical staging system but others have mainly reported the CD4 count at the development of pulmonary tuberculosis and this varied from 69 to 214 cells $\times 10^{6} / 1 .^{10}{ }^{30} 33$ People with extrapulmonary tuberculosis presented with the highest CD4 count in our study, and it was associated with a relatively longer survival, presumably because this is one of the few ADCs for which we are able to provide intensive and effective treatment.

There seemed to be generally a poor relation between median survival with a condition and the CD4 count; however, caution should be drawn from this finding owing to the relatively small size of this study. Overall, our survival by specific ADCs was generally shorter than in studies from developed countries. The median survival with wasting syndrome, Kaposi's sarcoma, and oesophageal candidiasis was less than 3.5 months compared with a range of 12-19.8 months in other reported studies. ${ }^{4} 52433{ }^{34}$ However, survival with cryptosporidial diarrhoea, HSV for more than 1 month, and extrapulmonary tuberculosis was also similar to that reported by studies in developed countries. ${ }^{17}{ }^{33}$ These latter conditions have a relatively high background level in rural Uganda. HSV is a common cause of genital ulcer in our population, and some of the cases we diagnosed may have represented lack of antivirals or superadded bacterial infection that prolonged the duration of episodes rather than indicating late stage disease. Although relatively few participants developed AIDS because of cryptosporidial diarrhoea for more than 1 month, their median survival exceeded 20 months and patients presented with a wide range of CD4 counts. Survival with this condition in developed countries ranges from around $5^{4}$ to 22.8 months. ${ }^{24}$ Flanigan et al compared HIV positive people with self limiting cryptosporidiosis (mean CD4 count 312 cells $\left.\times 10^{6} / 1\right)$ to those with persistent disease (mean CD 4 count 57 cells $\times 10^{6} / 1$ ). The odds of self limiting infection were 53 times greater in patients with CD4 counts of 150 cells $\times 10^{6} / 1 .^{35}$ Some of our participants presenting with cryptosporidial diarrhoea may have cleared their infection, but since we did not carry out repeated stool examination for the duration of their diarrhoea, their prolonged diarrhoea may have been due to other, or possibly repeated, infections.

\section{Conclusions}

We have described the initial ADCs, the CD4 counts at the development of these conditions, and survival in rural Uganda. In this study, survival for each condition was generally shorter and the median CD4 lymphocyte count around the time of AIDS diagnosis higher than studies reported from developed countries. However, the conditions with the longest survival (cryptosporidial diarrhoea, chronic HSV, and extrapulmonary tuberculosis) had a similar survival time to that in developed countries and these conditions have a high background level in this population and thus may be less specific markers of severe immunodeficiency in this population. The overall survival of 9.3 months from the diagnosis of AIDS is similar to that reported early in the HIV epidemic in developed countries. The lack of effective treatments for the ADCs may well contribute to the differences in survival.

This study was supported by the Medical Research Council and the Department for International Development of the United Kingdom. We wish to acknowledge Amanda Ross who did the preliminary analysis for this paper and thank all the cohort clinic staff, and the participants themselves.

Contributors: DM was project leader for the cohort, she designed the study and planned the analyses, and was the main lead in writing the paper; SM managed the cohort database and provided statistical support; $\mathrm{BM}, \mathrm{JO}$, and $\mathrm{MO}$ were the study clinicians who reviewed the participants and provided their clinicians who reviewed the participants and provided their clinical care; JW advised on the design of the study, and made major contributions to the writing of the paper; all
and contributed to the production of the paper.

1 Mocroft A, Johnson MA, Phillips AN. Factors affecting survival in patients with the acquired immunodeficiency syndrome. AIDS 1996;10:1057-65.

2 Turner BJ, Eppes S, McKee LJ, et al. A population-based comparison of the clinical course of children and adults with AIDS. AIDS 1995;9:65-72.

3 Petruckevitch A, Del Amo J, Phillips AN, et al. Disease progression and survival following specific AIDS-defining
conditions: a retrospective cohort study of 2048 HIVinfected persons in London. AIDS 1998;12:1007-13.

4 Friedland GH, Saltzman B, Vileno J, et al. Survival differences in patients with AIDS. $\mathcal{F}$ Acquir Immune Syndr 1991;4:144-53.

5 Gail MH, Tan W-Y, Pee D, et al for the Multicenter Hemophilia Cohort Study. Survival after AIDS diagnosis in a cohort of hemophilia patients. F Acquir Immune Syndr 1997; 15:363-9.

6 Hamilton JD, Hartigan PM, Simberkoff MS, et al. A controlled trial of early versus late treatment with zidovudine in symptomatic human immunodeficiency virus infection: Results of the Veterans Affairs Cooperative Study. N Engl f Med 1992;326:437-43.

7 Brodt HR, Kamps BS, Gute P, et al. Changing incidence of AIDS-defining illnesses in the era of antireroviral combination therapy. AIDS 1997;11:1731-8.

8 Weiss PJ, Wallace MR, Olsen PE, et al. Changes in the mix of AIDS-defining conditions. N Engl f Med 1993;329: 1962.

9 Porter K, Fairley CK, Wall PG, et al. AIDS defining diseases in the UK: the impact of PCP prophylaxis and twelve years in the UK: the impact of PCP prophylaxis
of change. Int $\mathcal{F}$ STD AIDS 1996;7:252-7.

10 Schwartländer B, Horsburgh CR, Hamouda O, et al. Changes in the spectrum of AIDS-defining conditions and decrease in CD4+ lymphocyte counts at AIDS manifestations in Germany from 1986 to 1991. AIDS 1992;6:41320 .

11 Chequer P, Herst N, Hudes ES, et al. Determinants of survival in adult Brazilian AIDS patients, 1982-1989. AIDS 1992; 6:483-7.

12 Kitayaporn D, Tansuphaswadikul S, Lohsomboon P, et al. Survival of AIDS patients in the emerging epidemic in Bangkok, Thailand. F Acquir Immune Defic Syndr 1996;11: $77-82$.

13 Morgan D, Malamba SS, Maude GH, et al. An HIV-1 natural history cohort and survival times in rural Uganda. AIDS 1997;11:633-40.

14 World Health Organisation. Acquired immune deficiency syndrome (AIDS): interim proposal for a WHO staging system for HIV-1 infection and disease. Wkly Epidemiol Rec 1990;65:221-8.

15 Lemp GF, Payne SF, Neal D, et al. Survival trends for patients with AIDS. $\mathscr{f} A M A$ 1990;263:402-6.

16 Moore RD, Hidalgo J, Sugland BW, et al. Zidovudine and the natural history of the acquired immunodeficiency syndrome. N Engl F Med 1991;324:1412-6.

17 Rogers PA, Whitmore-Overton SE, Evans BG, et al. Survival of adults with AIDS in the United Kingdom. Commun Dis Rep Rev 1997; 7:R93-100.

18 Ghirardini A, Puopolo M, Rossetti G, et al for the Italian Group on Congenital Coagulopathies. Survival after AIDS among Italian haemophiliacs with HIV infection. AIDS 1995;9:1351-6.

19 Mouton Y, Alfandiari S, Valette M, et al. Impact of protease inhibitors on AIDS-defining events and hospitalizations in 10 French AIDS reference centres. AIDS 1997;11: F101-5.

20 Fleming PL, Ward JW, Karon JM, et al. Declines in AIDS incidence and deaths in the USA: a signal change in the epidemic. AIDS 1998;12 (suppl A):S55-61. 
21 Ross JDC, Brettle R, Zhu C, et al. A comparison of AIDSdefining events and subsequent CDC stage IV events in IDUs and gay men. Int F STD AIDS 1994;5:419-23.

22 Fleming PL, Ciesielski CA, Byers RH. et al. Gender differences in reported AIDS-indicative diagnoses. F Infect Dis 1993;168:61-7.

$23 \mathrm{Hu}$ DJ, Fleming PL, Castro KG, et al. How important is race/ethnicity as an indicator of risk for specific AIDSdefining conditions? F Acquir Immune Defic Syndr 1995;10 374-80.

24 Saah AJ, Hoover DR, He Y, et al and the Multicenter AIDS cohort study. $\mathcal{f}$ Acquir Immune Defic Syndr 1994;7:287-95.

25 Lucas S, Goodgame R, Kocjan G, Serwadda D. Absence of pneumocystosis in Ugandan AIDS patients. AIDS 1989;3 p7-8.

26 Carme B, Mboussa J, Andzin M, et al. Pneumocystis carinii is rare in AIDS in Central Africa. Trans R Soc Trop Med Hyg is rare in AID

27 The Study Group for the MRC Collaborative Study of HIV infection in Women. Ethnic differences in women with HIV in

28 Hoover DR, Saah AJ, Bacellar $\mathrm{H}$ et al for the Multicenter AIDS Cohort Study. Clinical manifestations of AIDS in the era of pneumocystis prophylaxis. $N$ Engl $f$ Med 1993;329:1922-6
29 Phillips AN, Pezzoti P, Lepri AC, et al. CD4 lymphocyte counts as a determinant of the time from HIV seroconversion to AIDS and death: evidence from the Italian

30 Crowe SM, Carlin JB, Stewart KI, et al. Predictive value of CD4 lymphocyte numbers for the development of opportunistic infections and malignancies in HIV-infected persons. F Acquir Immune Defic Syndr 1991;4: 770-6.

31 Mocroft A, Youle M, Morcinek J et al for the Royal Free/Chelsea and Westminster Hospitals Collaborative Group. Survival after diagnosis of AIDS: a prospective observational study of 2625 patients. BMF 1997;314:40913.

32 Wannamethee SG, Sirivichayakul S, Phillips AN, et al. Clinical and immunological features of human immunodeficiency virus infection in patients from Bangkok, Thailand. Int $\mathcal{A}$ Epidemiol 1998;27:289-95.

33 Luo K, Law M, Kaldor JM, et al. The role of initial AIDSdefining illness in survival following AIDS. AIDS 1995;9: defining

34 Mocroft AJ, Lundgren JD, Monforte AD, et al for the AIDS in Europe Study Group. Survival of AIDS patients according to type of AIDS-defining event. Int $\mathcal{f}$ Epidemiol

35 Flanigan $\mathrm{T}$, Whalen $\mathrm{C}$, Turner J, et al. Cryptosporidium infection and CD4 counts. Ann Intern Med 1992;116:8402. 